\title{
The X-inactivation trans-activator $R$ nf12 is negatively regulated by pluripotency factors in embryonic stem cells
}

\author{
Pablo Navarro - Michael Moffat • Nicholas P. Mullin • \\ Ian Chambers
}

Received: 1 March 2011 / Accepted: 21 April 2011/Published online: 5 May 2011

(C) The Author(s) 2011. This article is published with open access at Springerlink.com

\begin{abstract}
X-inactivation, the molecular mechanism enabling dosage compensation in mammals, is tightly controlled during mouse early embryogenesis. In the morula, X-inactivation is imprinted with exclusive silencing of the paternally inherited X-chromosome. In contrast, in the post-implantation epiblast, X-inactivation affects randomly either the paternal or the maternal X-chromosome. The transition from imprinted to random X-inactivation takes place in the inner cell mass (ICM) of the blastocyst from which embryonic stem (ES) cells are derived. The trigger of X-inactivation, Xist, is specifically downregulated in the pluripotent cells of the ICM, thereby ensuring the reactivation of the inactive paternal X-chromosome and the transient presence of two active X-chromosomes. Moreover, Tsix, a critical cis-repressor of Xist, is upregulated in the ICM and in ES cells where it imposes a particular chromatin state at the Xist promoter that ensures the establishment of random $\mathrm{X}$-inactivation upon differentiation. Recently, we have shown that key transcription
\end{abstract}

Electronic supplementary material The online version of this article (doi:10.1007/s00439-011-0998-5) contains supplementary material, which is available to authorized users.

P. Navarro $(\varangle) \cdot$ M. Moffat · N. P. Mullin · I. Chambers $(\square)$ MRC Centre for Regenerative Medicine,

Institute for Stem Cell Research, School of Biological Sciences,

University of Edinburgh, King's Buildings,

West Mains Road, Edinburgh EH9 3JQ, Scotland, UK

e-mail: pablo.navarro@ed.ac.uk

I. Chambers

e-mail: ichambers@ed.ac.uk

Present Address:

M. Moffat

MRC Human Genetics Unit, Western General Hospital,

University of Edinburgh, Edinburgh, Scotland, UK factors supporting pluripotency directly repress Xist and activate Tsix and thus couple Xist/Tsix control to pluripotency. In this manuscript, we report that Rnf12, a third $\mathrm{X}$-linked gene critical for the regulation of $\mathrm{X}$-inactivation, is under the control of Nanog, Oct4 and Sox2, the three factors lying at the heart of the pluripotency network. We conclude that in mouse ES cells the pluripotency-associated machinery exerts an exhaustive control of X-inactivation by taking over the regulation of all three major regulators of X-inactivation: Xist, Tsix, and Rnf12.

\section{Introduction}

In her seminal manuscripts proposing random X-inactivation as the mechanism underlying dosage compensation in mammals (Lyon 1961; Lyon 1962), Mary Lyon suggested this process must occur early during female embryonic development, around the formation of the late blastocyst. This first approximation was confirmed by means of single cell blastocyst injections (Gardner and Lyon 1971), cytogenetical observation of the heterochromatic X-chromosome (Plotnick et al. 1971; Takagi and Sasaki 1975), and biochemical analysis of X-linked genes encoding metabolic enzymes at different developmental stages (Monk and Kathuria 1977): these studies established that cells of the inner cell mass (ICM) of the blastocyst carry two active $\mathrm{X}$-chromosomes, whilst in the trophectoderm the paternally inherited X-chromosome is inactivated. The idea that emerged from this was that $\mathrm{X}$-inactivation is initially established upon differentiation, either imprinted in extraembryonic tissues or randomly in the embryo proper. This enduring concept was well supported by analysis of embryonic stem (ES) cells: random X-inactivation is only established upon differentiation (Rastan and Robertson 
1985). The delivery of important molecular insights of the $\mathrm{X}$-inactivation process, and their study in the pre-implantation embryo challenged this initial dogma (reviewed in Navarro and Avner 2009). In particular, the discovery of the X-linked non-coding Xist gene (Brown et al. 1991; Borsani et al. 1991; Brockdorff et al. 1991) and of the mechanisms by which it triggers $\mathrm{X}$-inactivation in cis, were critical milestones.

Xist produces a $17 \mathrm{~kb}$-long non-coding RNA exclusively expressed from the inactive X-chromosome (Xi) of female cells that mediates $\mathrm{X}$-wide silencing. Xist RNA structures a nuclear compartment from which the transcriptional machinery is excluded and members of the Polycomb group recruited, leading to the silencing of X-linked genes and the initiation of a cascade of chromatin events that end up with the heterochromatinisation of the X-chromosome (reviewed in $\mathrm{Ng}$ et al. 2007). In both male and female ES cells, Xist is consistently repressed and this might be sufficient to keep all X-chromosomes active (Xa) (reviewed in Navarro and Avner 2009). Indeed, forced expression of Xist in ES cells leads to X-inactivation even before differentiation (Wutz and Jaenisch 2000), indicating that Xist repression is the most critical event required to abolish $\mathrm{X}$-inactivation in undifferentiated cells. Notably, upon differentiation, Xist is monoallelically upregulated exclusively in female cells, thereby triggering random $\mathrm{X}$-inactivation (reviewed in Navarro and Avner 2009). The analysis of Xist RNA and associated heterochromatin marks in early mouse embryos radically changed our conception of the developmental dynamics of X-inactivation (Mak et al. 2004; Okamoto et al. 2004). Although all cells of the ICM appeared to lack an $\mathrm{Xi}$, the cells of the cleavage-stage morula were found to carry an $\mathrm{Xi}$. Further, it was shown that in the morula, the $\mathrm{Xi}$ is always the paternal X-chromosome. Therefore, X-inactivation is established much earlier than previously thought, at the two to four cells transition, under the form of imprinted $\mathrm{X}$-inactivation. The acquisition of pluripotency, a characteristic restricted to the cells of the ICM, and more particularly the expression of Nanog (Chambers et al. 2003), a critical transcription factor specifying pluripotency, leads to the reactivation of the paternal $\mathrm{Xi}$ exclusively in the ICM (Silva et al. 2009). Strikingly, Xist silencing and Xi reactivation also accompany the acquisition of pluripotency in vitro, either after somatic-ES cells fusions (Tada et al. 2001), nuclear cloning (Eggan et al. 2000), or the generation of induced pluripotent stem cells (Stadtfeld et al. 2008). Understanding how $\mathrm{X}$-inactivation is abolished in pluripotent cells is, therefore, important not only for $\mathrm{X}$-inactivation, but also to the wider field of epigenetics and cellular reprogramming.

Previously, we have shown that Nanog, Oct4 and Sox2, the three main transcription factors supporting pluripotency (reviewed in Chambers and Tomlinson 2009), bind within Xist intron 1 in ES cells and maintain Xist repression until differentiation (Navarro et al. 2008). This provided a simple scenario accounting for the systematic coupling of $\mathrm{Xi}$ reactivation with the acquisition of pluripotency. In contrast to our expectations, however, the deletion of Xist intron 1 is not accompanied by increased levels of Xist expression in undifferentiated female ES cells (Barakat et al. 2011). This indicates that Nanog, Oct4 and Sox 2 action at Xist is not sufficient by itself to keep Xist in check in undifferentiated ES cells. Hence, additional ES-specific repressive mechanisms of Xist must exist. In this scenario, the strong ES-specific activity of Tsix, a non-coding antisense chromatin repressor of Xist (Navarro et al. 2005, 2006; Sado et al. 2005; Sun et al. 2006, Ohhata et al. 2008, Navarro et al. 2009), and the fact that other pluripotency-associated factors, namely Klf4, c-Myc and Rex1, couple Tsix activity to pluripotency (Navarro et al. 2010), is compelling. However, neither Xist intron 1 deletion (Barakat et al. 2011) nor Tsix deletion (Lee and Lu 1999) can individually trigger the level of Xist upregulation that is compatible with the initiation of X-inactivation in undifferentiated ES cells. It remains possible that abrogating simultaneously both pluripotency-coupled repressive arms might be sufficient to do so. An alternative, not mutually exclusive, hypothesis involves a third gene recently incorporated to the short list of X-linked regulators of X-inactivation: Rnf12, a gene encoding an E3 ubiquitin ligase.

Rnf12, located several hundred kilobases upstream of $X i s t / T s i x$, was initially identified as an inducer of Xist upregulation during random $X$-inactivation (Jonkers et al. 2009). Subsequently, the involvement of Rnf12 during imprinted X-inactivation was demonstrated (Shin et al. 2010). Transgenic male ES cells overexpressing Rnf12 induce ectopic inactivation of the single X-chromosome upon differentiation, and in female lines a large fraction of the cells inactivates both X-chromosomes (Jonkers et al. 2009). Thus, it appears that Xist upregulation is triggered in differentiating female cells by virtue of the two copies of Rnf12 that they carry, as opposed to the single copy present in male cells (Jonkers et al. 2009). In agreement, Rnf12 has been shown to act in trans on the minimal Xist promoter region without interfering with Nanog, Oct4, Sox2, and Tsix activity (Barakat et al. 2011). Importantly, in female ES cells overexpressing Rnf12, a significant proportion of cells already displays Xist RNA accumulation before differentiation (Jonkers et al. 2009). This signifies that, to ensure Xi reactivation in pluripotent cells, Rnf12 expression must be downregulated. In this manuscript, we demonstrate the control mediated by pluripotency-factors on $\mathrm{X}$-inactivation includes the downregulation of Rnfl2 by Nanog, Oct4 and Sox2. 


\section{Methods}

\section{Cell lines}

All lines used in this study have been previously described. The inducible deletion of Nanog was performed by treating $\mathrm{RCN} \beta \mathrm{H}$ cells with tamoxifen. These cells carry: (1) an homozygous deletion of Nanog endogenous alleles, (2) a Cre:ERT2 expressing transgene at the Rosa26 locus, and (3) a loxP-flanked Nanog expressing transgene randomly integrated (Chambers et al. 2007). These cells were previously used to generate Nanog-null cells by plating tamoxifen treated cells at clonal density and expanding Nanog-null clones (RCN $\beta \mathrm{H}(\mathrm{t}))$ (Chambers et al. 2007). To restore Nanog expression in $\mathrm{RCN} \beta \mathrm{H}(\mathrm{t})$ cells, a Nanog expression vector carrying a puromycin resistance gene was electroporated and cells selected for 6 days in the presence of $1 \mu \mathrm{g} / \mathrm{ml}$ of puromycin.

Nanog-overexpressing cells (EF4) were generated by random integration of CAG-driven Nanog cDNA in wildtype E14Tg2a ES cells (Chambers et al. 2003).

Oct4 inducible knock-out cells have been previously described (Niwa et al. 2000). Briefly, these cells carry two Oct4-null alleles and Oct4 expression is sustained by a doxycycline suppressible transgene. Treatment of these cells with $1 \mu \mathrm{g} / \mathrm{ml}$ of doxycycline triggers rapid and efficient silencing of the Oct4 expressing transgene.

\section{Chromatin immunoprecipitation}

Twenty million cells were resuspended in $3 \mathrm{ml}$ of prewarmed DMEM-FCS $10 \%$ and crosslinked with $1 \%$ formaldehyde (Sigma) for $10 \mathrm{~min}$ at room temperature. The reaction was quenched with $0.125 \mathrm{mM}$ glycine for $5 \mathrm{~min}$ at room temperature. Cells were spun down for $3 \mathrm{~min}$ at $1,300 \mathrm{rpm}$ at $4^{\circ} \mathrm{C}$, and washed twice with cold PBS-1X (Invitrogen). Cell pellets were then vigorously resuspended in $300 \mu \mathrm{l}$ of swelling buffer ( $5 \mathrm{mM}$ Pipes $\mathrm{pH}$ $8,85 \mathrm{mM} \mathrm{KCl}$ ) freshly supplemented with $1 \mathrm{X}$ protease inhibitor cocktail (Roche) and 0.5\% NP-40. The suspension was incubated for $20 \mathrm{~min}$ on ice with occasional shaking. Nuclei were spun down in $15 \mathrm{ml}$ conical tubes for $10 \mathrm{~min}$ at $1,500 \mathrm{rpm}$ at $4^{\circ} \mathrm{C}$ and resuspended in $1.5 \mathrm{ml}$ of TSE150 (0.1\% SDS, $1 \%$ Triton, $2 \mathrm{mM}$ EDTA, $20 \mathrm{mM}$ Tris-HCl $\mathrm{pH} 8,150 \mathrm{mM} \mathrm{NaCl}$ ) buffer, freshly supplemented with $1 \mathrm{X}$ protease inhibitor cocktail. Samples were sonicated at $4{ }^{\circ} \mathrm{C}$ in $15 \mathrm{ml}$ conical tubes using a Bioruptor (Diagenode) for 5 cycles of 10 min divided into $30 \mathrm{~s}$ ON-30 s OFF subcycles at maximum power. Chromatin was then transferred into $1.5 \mathrm{ml}$ tubes and centrifuged for $30 \mathrm{~min}$ at $14,000 \mathrm{rpm}$ at $4^{\circ} \mathrm{C}$. Soluble chromatin was aliquoted and stored at $-80^{\circ} \mathrm{C}$ until use. Twenty microlitres were used for quantity and quality controls of the DNA.
For each experiment, the required amount of chromatin was defrosted and pre-cleared for $1 \mathrm{~h} 30$ with rotation at $4^{\circ} \mathrm{C}$ in $1 \mathrm{ml}$ of TSE150 with $50 \mu \mathrm{l}$ of $\mathrm{pA} / \mathrm{pG}$ Sepharose beads (Sigma) $50 \%$ slurry, previously blocked with $500 \mu \mathrm{g} / \mathrm{ml}$ of molecular grade BSA (Roche) and $1 \mu \mathrm{g} / \mathrm{ml}$ of yeast tRNA (Invitrogen). Pre-cleared chromatin was transferred into fresh tubes after 1 min centrifugation at $3,000 \mathrm{rpm}$ and aliquoted accordingly (20 $\mu \mathrm{g}$ of DNA per ChIP). Twenty micrograms of diluted chromatin were aliquoted for input DNA extraction and precipitation. Immunoprecipitation with specific antibodies [ $1 \mu \mathrm{g}$ homemade rabbit anti-Nanog (Mullin et al. 2008), $1 \mu \mathrm{g}$ goat anti-Oct4 (Santa Cruz, sc-8628), $1 \mu \mathrm{g}$ goat anti-Sox2 (Santa Cruz, sc-17320)] was performed overnight with rotation at $4{ }^{\circ} \mathrm{C}$, in a final volume of $500 \mu \mathrm{l}$. Immunocomplexes were recovered with $50 \mu 1$ of blocked $\mathrm{pA} / \mathrm{pG}$ Sepharose beads $50 \%$ slurry for $1 \mathrm{~h} 30$ with rotation at $4^{\circ} \mathrm{C}$. Beads were recovered by $1 \mathrm{~min}$ centrifugation at $3,000 \mathrm{rpm}$ and washed at room temperature in $1 \mathrm{ml}$ of TSE150, TSE500 (0.1\% SDS, $1 \%$ Triton, $2 \mathrm{mM}$ EDTA, $20 \mathrm{mM}$ Tris- $\mathrm{HCl} \mathrm{pH} 8,500 \mathrm{mM} \mathrm{NaCl}$ ), washing buffer (10 mM Tris- $\mathrm{HCl} \mathrm{pH} 8,0.25 \mathrm{M} \mathrm{LiCl}, 0.5 \%$ NP40, $0.5 \%$ Na-Deoxycholate, $1 \mathrm{mM}$ EDTA), and twice in TE (10 mM Tris-HCl pH8, $1 \mathrm{mM}$ EDTA). Each wash was performed for $5 \mathrm{~min}$ with rotation at room temperature. After the last wash, elution was performed in $100 \mu \mathrm{l}$ of elution buffer (1\% SDS, $10 \mathrm{mM}$ EDTA, $50 \mathrm{mM}$ Tris-HCl pH8) for $15 \mathrm{~min}$ at $65^{\circ} \mathrm{C}$ after vigorous vortexing. Eluates were collected after $1 \mathrm{~min}$ centrifugation at 14,000 rpm, and the beads rinsed in $150 \mu \mathrm{l}$ of TE-SDS $1 \%$. After 1 min centrifugation at $14,000 \mathrm{rpm}$, the supernatant was pooled with the corresponding first eluate. Crosslinking of ChIP and input fractions was reversed overnight at $65^{\circ} \mathrm{C}$, followed by proteinase $\mathrm{K}$ treatment (invitrogen), phenol/ chloroform extraction and ethanol precipitation. DNA pellets corresponding to the input fractions were resuspended in $300 \mu \mathrm{l}$ of water, whilst those corresponding to the ChIP fraction were resuspended in $150 \mu \mathrm{l}$.

\section{RNA extraction and reverse transcription}

One to five million cells were lysed in TRIZOL (Invitrogen) and RNA was then chloroform extracted and isopropanol precipitated. After DNase treatment (Quiagen), RNA was phenol/chloroform re-extracted, ethanol precipitated, resuspended in water and quantified.

One to $4 \mu \mathrm{g}$ of RNA were used per RT reaction. RNA was denatured in the presence of $1 \mu \mathrm{g}$ of random hexamers (Roche) for $5 \mathrm{~min}$ at $90^{\circ} \mathrm{C}$, and reverse transcribed in a final volume of $20 \mu \mathrm{l}$ with $100 \mathrm{U}$ of SuperScriptII (Invitrogen) at $42^{\circ} \mathrm{C}$ for $60 \mathrm{~min}$ followed by heat inactivation at $70^{\circ} \mathrm{C}$ for $15 \mathrm{~min}$. Synthesised cDNAs were diluted in $280 \mu \mathrm{l}$ of water and stored at $-20^{\circ} \mathrm{C}$ until used. 


\section{Real-time PCR}

Q-PCR was performed in 384-well plates with a 480 LightCycler (Roche) using LightCycler 480 SYBR Green I Master (Roche). All reactions were performed in duplicate. Five microliters of DNA were used per reaction.

Standard curves of all primers were performed to check for efficient amplification (above 90\%). Melting curves were also generated to verify production of single DNA species with each primer pair. All primer sequences are available upon request.

Relative levels of expression in each RT-(Q)PCR assay were obtained through the $\Delta \Delta \mathrm{Ct}$ method, using $T b p$ mRNA levels as a reporter in all experiments.

Enrichment levels in ChIP assays are expressed as enrichment levels as compared to the Actin promoter. Essentially, for each analysed position, the $\Delta \mathrm{Ct}$ method was used to calculate a ChIP over input ratio that was corrected by the appropriate dilution factor of each analysed fraction. To calculate enrichment levels, values obtained for the Rnfl2 upstream region were divided by those obtained for the Actin promoter.

Primer pairs to detect binding of Nanog, Oct4 and Sox2 upstream of Rnfl2 were designed across positive ChIP-Seq hits publicly available (Chen et al. 2008). The Actin promoter was chosen as a negative control on the basis of the absence of binding observed in the same data set. The sequences are: Rnf12-4 kb F: CAGCCTCTGGCTCTACC AGT and R: GTGACCTGCTGGGGAGAATA; Rnf12-5 kb F: GCCTGTCAAACGTCCTGTTTA and R: GGAGGTTG TGGGAGAAACAA; Actin F: CCGTTCCGAAAGTTG CCTT and R: CGCCGCCGGGTTTTATA.

\section{Results}

Rnf12 is a target of Nanog in undifferentiated mouse ES cells

Rnf12 protein levels have been shown to increase moderately during ES cells differentiation (Barakat et al. 2011). To assess whether this increase is mediated by an increase of mRNA levels, we first conducted RT-(Q)PCR in undifferentiated and differentiating ES cells. Efficient differentiation was evaluated by measuring Nanog mRNA levels, and as expected we found consistent downregulation of Nanog after 3 days of RA-mediated differentiation (Fig. 1a). Under these conditions, we found a two to threefold increase of Rnf12 expression in RA-differentiated cells, in both males (E14Tg2a) and females (LF2) though the absolute levels of Rnf12 mRNA showed the expected 2 to 1 ratio between $\mathrm{XX}$ and $\mathrm{XY}$ cells (Fig. 1b). This suggests that similar principles of regulation of Rnfl2 apply

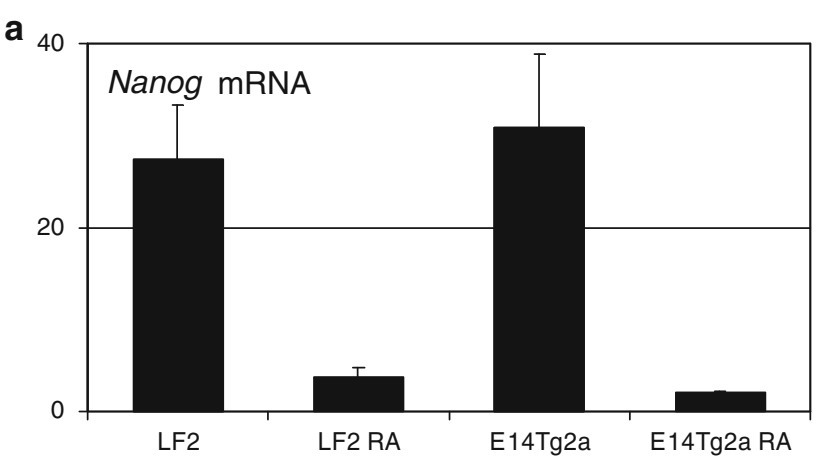

b 4

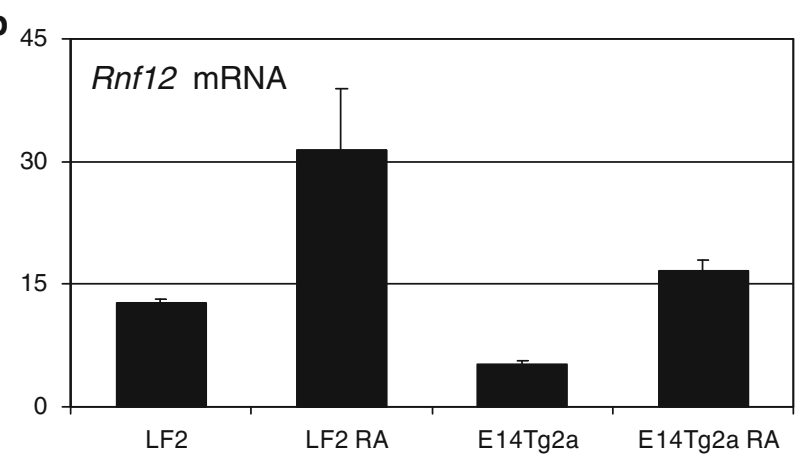

C

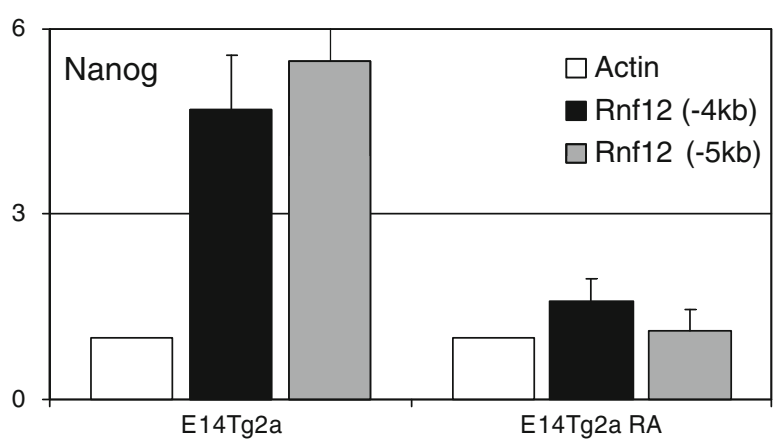

Fig. 1 Rnf12 is a direct target of Nanog in ES cells. Male (E14Tg2a) and female (LF2) ES cells were differentiated with retinoic acid for 3 days, and Nanog (a) and Rnf12 (b) mRNA levels measured by RT(Q)PCR before and after treatment. Statistical significance of Rnf12 expression differences was assessed with a paired $t$ test $[p$ value of LF2-d3/d0 $<0.03(n=3)$ and of E14Tg2a-d3/d0 $<0.01(n=3)]$. c ChIP analysis of Nanog binding at two regions located 4 and $5 \mathrm{~kb}$ upstream of the transcription start site in undifferentiated and RAdifferentiated male ES cells. All values represent averages of independent cell cultures \pm SEM

during male and female differentiation and that the sole presence of two alleles in females underlies the femalespecific action of Rnf12.

The correlation between Nanog downregulation and Rnf12 upregulation during ES cells differentiation, and the fact that in the embryo the reactivation of the $\mathrm{Xi}$ closely follows Nanog protein expression in the ICM (Silva et al. 2009), suggests that Nanog might be important for Rnfl2 regulation. Interestingly, genome-wide analysis suggests Rnf12 might be a direct target of Nanog (Chen et al. 2008). To confirm this, we determined whether two regions 
located 4 and $5 \mathrm{~kb}$ upstream of Rnfl2 and identified by ChIP-Seq as positive Nanog hits (Chen et al. 2008) show enrichment for Nanog in ChIP-(Q)PCR assays. A five to sixfold enrichment was measured at these two regions in undifferentiated ES cells but not in RA-differentiating negative controls (Fig. 1c). These results, therefore, suggest that Nanog is a direct regulator of Rnfl2 in undifferentiated ES cells.

Nanog acts as a repressor of $R n f 12$ expression in undifferentiated ES cells

The negative correlation existing between Nanog binding and Rnf12 expression during ES cells differentiation (Fig. 1) suggests that Nanog may act as a negative regulator of Rnf12. To assess the modality of Nanog action at Rnf12, we first analysed the consequences of overexpressing Nanog. To do this, we used a cell line (EF4) carrying a randomly integrated Nanog-expressing transgene (Chambers et al. 2003) that confers high levels of Nanog mRNA expression (Fig. 2a). In EF4, binding of Nanog at both the -4 and $-5 \mathrm{~kb}$ regions of the Rnf12 locus is greatly increased, with enrichment levels being around two to threefold higher than in control E14Tg2a ES cells (Fig. 2b). Given the fact that in EF4 cells Nanog protein is elevated approximately fivefold relative to wild-type cells (Yates and Chambers 2005), this implies that Nanog binding at Rnf12 in wild-type cells is not saturated, at least at the population level, though it may be saturated in EF4 cells. Since in wild-type cells Nanog is heterogeneously expressed (Chambers et al. 2007), with a significant fraction expressing low or undetectable Nanog protein, the increase of binding in EF4 likely reflects the homogeneity of Nanog expression and binding achieved by means of transgenic Nanog expression. Importantly, in EF4 ES cells, the expression of Rnf12 is reduced by about $50 \%$ (Fig. 2c).

To consolidate this observation, we took advantage of Nanog-null ES cells $(\mathrm{RCN} \beta \mathrm{H}(\mathrm{t})$, Chambers et al. 2007) in which neither Nanog expression (Fig. 2a) nor binding at Rnf12 are detected (Fig. 2b). In these cells, Rnf12 transcripts were found upregulated by around twofold, as expected for Nanog acting as a repressor (Fig. 2c). Next, we investigated whether Rnf12 upregulation is a primary, early consequence of Nanog depletion. To do this, we used $\operatorname{RCN} \beta \mathrm{H}$ cells, the parental line of $\operatorname{RCN} \beta \mathrm{H}(\mathrm{t})$. In $\mathrm{RCN} \beta \mathrm{H}$ ES cells, both Nanog alleles have been deleted and Nanog expression is supported by a randomly integrated transgene in which the Nanog open reading frame is flanked by loxP sites. Moreover, RCN $\beta$ H express a Cre:ERT2 fusion protein from the constitutive Rosa26 locus. Upon treatment of these cells with tamoxifen, the Cre:ERT2 fusion protein translocates into the nucleus and mediates the deletion of the Nanog-expressing transgene (Chambers et al. 2007). a

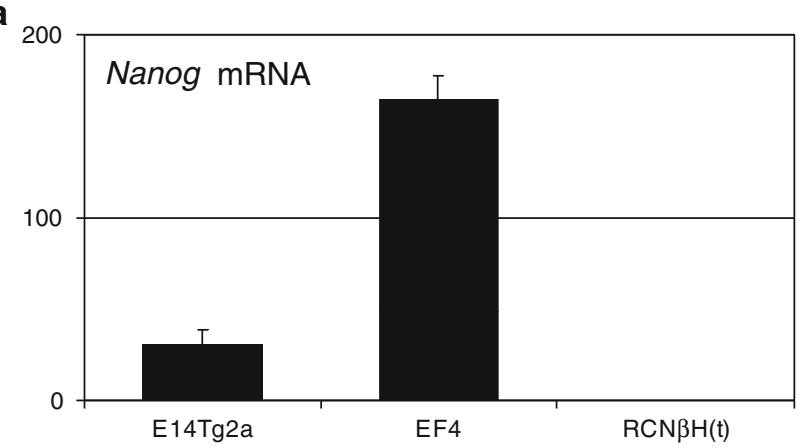

b

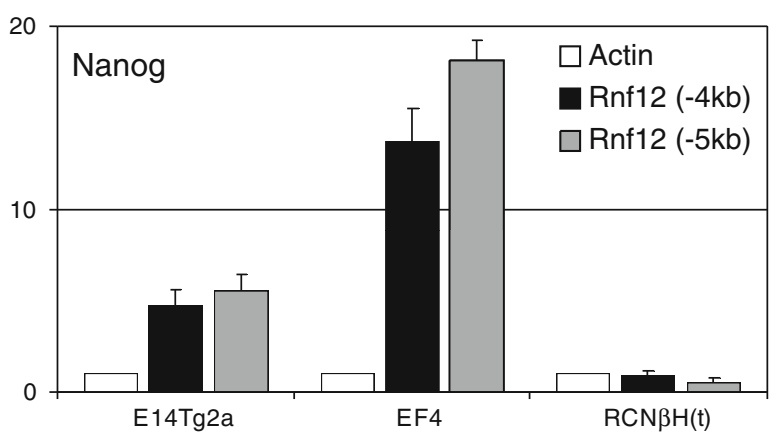

C

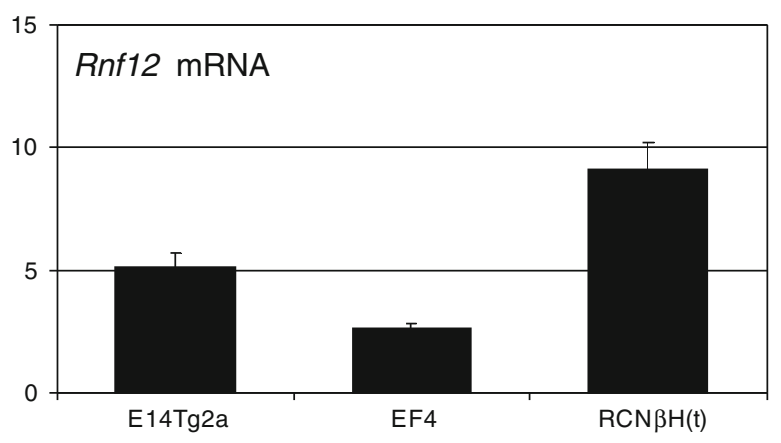

Fig. 2 Rnf12 is downregulated by Nanog in ES cells. Analysis of Nanog mRNA levels (a) binding at the Rnf12 locus (b) and Rnf12 mRNA levels (c) in wild-type E14Tg2a ES cells, Nanog-overexpressing ES cells (EF4), and Nanog-null ES cells $(\mathrm{RCN} \beta \mathrm{H}(\mathrm{t}))$. All values represent averages of independent cell cultures \pm SEM. Statistical significance of Rnf12 expression differences was assessed with an unpaired $t$ test $[p$ value of $\mathrm{EF} 4 / \mathrm{wt}<0.03(n=3)$ and of $\mathrm{RCN} \beta \mathrm{H}(\mathrm{t}) / \mathrm{wt}$ $<0.03(n=3)]$

$\mathrm{RCN} \beta \mathrm{H}$ cells were treated with tamoxifen for 3 days and RNAs collected daily. Nanog mRNA levels decrease strongly within the first $24 \mathrm{~h}$ of treatment, and reach background levels after $48 \mathrm{~h}$ (Fig. 3a). Within the first $24 \mathrm{~h}$ of tamoxifen treatment, Rnf12 mRNA increases to levels similar to that detected in established Nanog-null cells (Fig. 3b). Together with our ChIP analysis, this result suggests that the alteration of Rnfl2 expression observed in established Nanog-null or overexpressing lines is due to a direct action of Nanog on Rnfl2.

Next, we tested the reversibility of Rnfl2 upregulation observed in Nanog-null cells. To do this, a Nanog-expression vector was stably integrated in $\mathrm{RCN} \beta \mathrm{H}(\mathrm{t}) \mathrm{ES}$ cells and RNA 

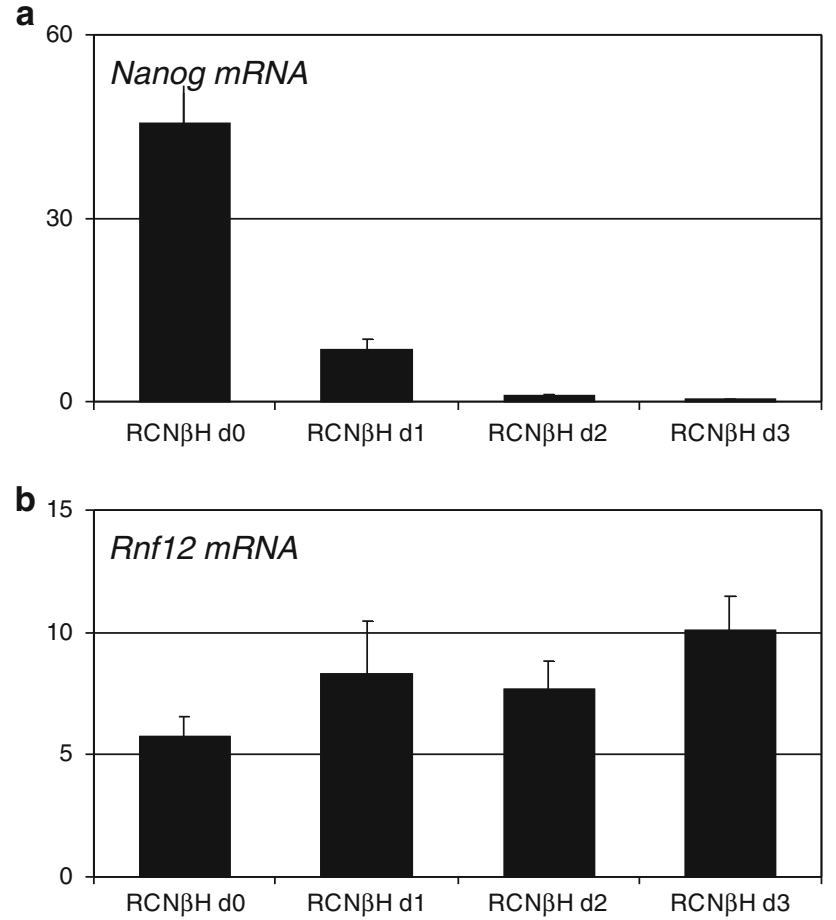

Fig. 3 Rnf12 upregulation arises rapidly following Nanog depletion. Analysis of Nanog (a) and Rnf12 (b) mRNA levels in inducible Nanog-null $\mathrm{RCN} \beta \mathrm{H}$ cells treated with tamoxifen for the indicated number of days. All values represent averages of independent cell cultures \pm SEM. Statistical significance of Rnf12 expression differences was assessed with a paired $t$-test. Although there is a clear trend from day 1 onwards, clear statistical significance is only reached after 3 days of treatment [ $p$ value of $\mathrm{d} 3 / \mathrm{d} 0<0.03(n=10)$ ], when Nanog expression is reduced to about $0.1 \%$ of untreated cells

and chromatin prepared. Evaluation of Nanog mRNA levels (Fig. 4a) indicates restoration of Nanog expression to levels similar to that of wild-type ES cells (Fig. 1a), indicating that the analysis is performed in physiological conditions regarding the level of Nanog expression. Compared to empty vector transfectants, the re-expression of Nanog in Nanognull cells leads to efficient binding of Nanog at the -4 and $-5 \mathrm{~kb}$ sites of the Rnfl2 upstream region (Fig. 4b), with identical levels of enrichment to those observed in wild-type cells (Fig. 1c). Under these conditions, Rnf12 mRNA levels (Fig. 4c) decline back to wild-type levels (Fig. 1b), whilst the cells transfected with the empty vector express similar levels of Rnfl2 than untransfected $\mathrm{RCN} \beta \mathrm{H}(\mathrm{t})$ ES cells (Fig. 2c). Taking all our observations together, we conclude that Nanog acts as a reversible repressor of Rnfl2 expression in ES cells.

Nanog-independent binding of Oct4 and Sox 2 at the Rnfl2 upstream region

In the absence of Nanog binding to the Rnfl2 upstream region, Rnfl2 is twofold upregulated in male ES cells.

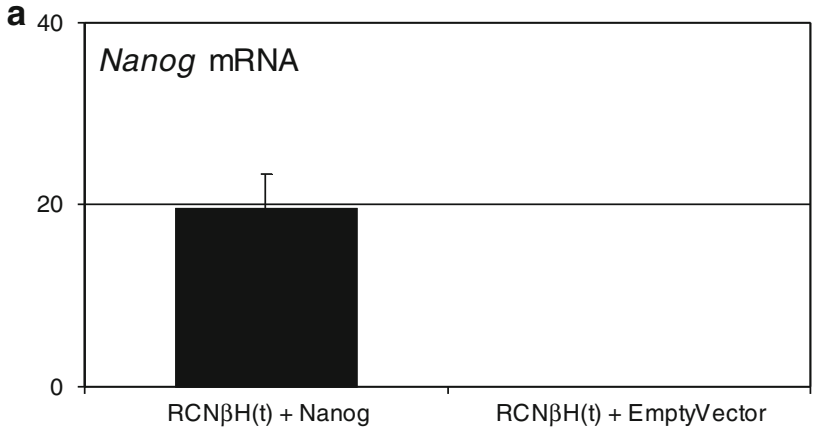

b
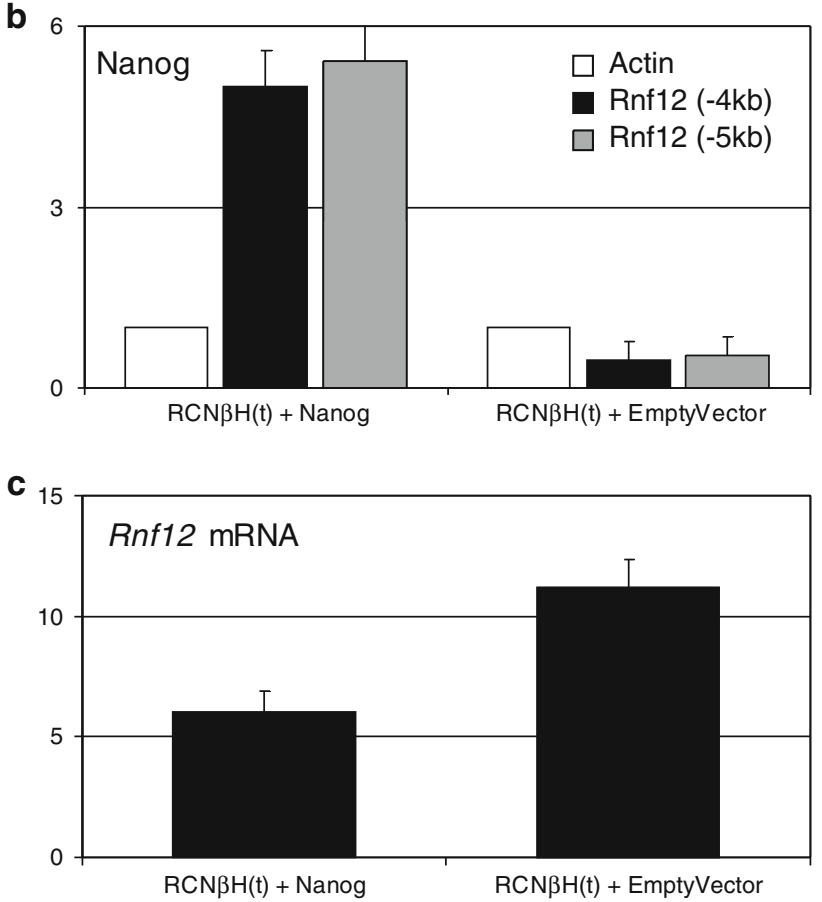

Fig. 4 Rnf12 upregulation in Nanog-null ES cells is reversible. Analysis of Nanog mRNA levels (a) binding at the Rnf12 locus (b) and Rnf12 mRNA levels (c) in $\mathrm{RCN} \beta \mathrm{H}(\mathrm{t})$ Nanog-null cells transfected with either a Nanog-expression vector or an empty vector. All values represent averages of independent cell cultures \pm SEM. Statistical significance of Rnf12 expression differences was assessed with a paired $t$ test ( $p$ value of Nanog/empty $<0.03(n=3)$ ]

However, the level reached in differentiating male ES cells is about threefold as compared to that observed in wildtype undifferentiated cells. This indicates that Nanog depletion in ES cells does not recapitulate entirely the mechanisms leading to Rnf12 upregulation during differentiation. Additional repressors of Rnf12 might exist in ES cells.

Genome-wide localisation studies of transcription factor binding in ES cells have shown that Nanog tends to bind at chromatin sites overlapping or just adjacent to those bound by Oct 4 and Sox 2 (Chen et al. 2008). More importantly, at Xist intron 1 Nanog binds with Oct4 and Sox 2 to repress Xist transcription (Navarro et al. 2008). Therefore, we 
hypothesised that Oct4 and Sox 2 bind with Nanog at the Rnf12 upstream region. We performed ChIP assays with Oct4 (Fig. 5a) and Sox2 (Fig. 5b) antibodies in ES cells. Both factors were found to bind at the -4 and $-5 \mathrm{~kb}$ sites of the Rnf12 upstream region, with levels of enrichment about four to fivefold higher than those measured at the beta-actin negative control. Importantly, in RA-treated differentiating ES cells, binding of both Oct4 and Sox 2 is totally abolished. This result suggests that Oct4 and Sox 2
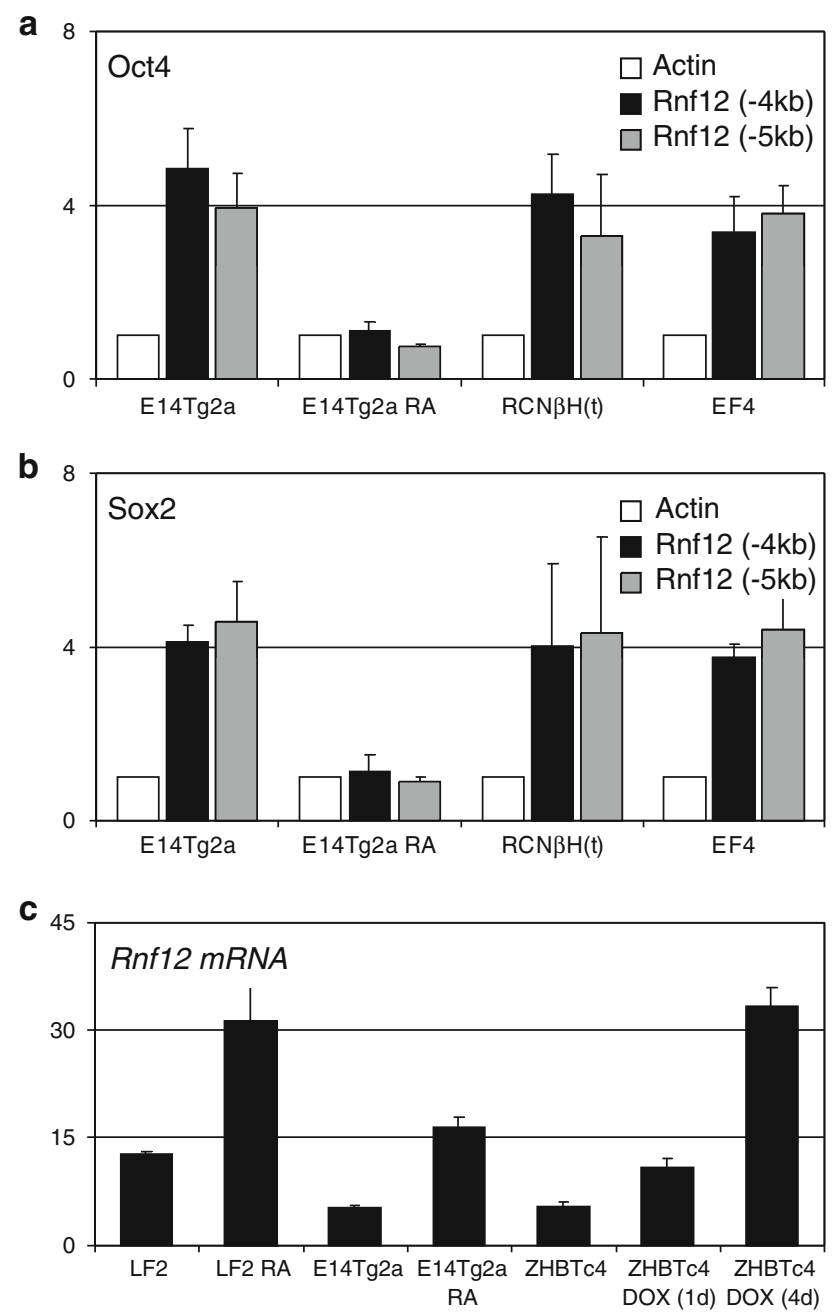

Fig. 5 Oct 4 and Sox 2 also act as Rnf12 repressors in ES cells. Analysis of Oct4 (a) and Sox2 (b) binding at the Rnf12 upstream region in the indicated cell lines. (c) Comparison of Rnf12 expression in different cell lines and conditions. ZHBTc4 ES cells are doxycycline inducible Oct4-null ES cells. All values represent averages of independent cell cultures \pm SEM. Statistical significance of Rnf12 expression differences in doxycycline-treated ZHBTc 4 cells was assessed with a paired $t$ test $[p$ value of $\mathrm{d} 1 / \mathrm{d} 0$ and $\mathrm{d} 4 / \mathrm{d} 0<0.01$ ( $n=6$ and 4, respectively)]. An unpaired $t$ test further confirmed that the level of Rnf12 mRNA reached in doxycycline-treated ZHBTc4 is significantly higher than that measured in RA-treated E14Tg2a cells $(p$ value $<0.01)$ cooperate with Nanog to bring about efficient downregulation of Rnf12.

To determine if Nanog is required or at least influences the binding of Oct 4 and Sox 2 at the Rnf 12 locus, we first analysed Oct 4 and Sox 2 binding at the -4 and $-5 \mathrm{~kb}$ regions in cells displaying increased binding of Nanog and found that neither Oct4 nor Sox 2 exhibit increased binding at Rnf12 (EF4, Fig. 5a, b). Moreover, in Nanog-null ES cells both Oct 4 and Sox 2 remain associated to the Rnf 12 upstream region at levels of enrichment indistinguishable from those observed in wild-type E14Tg2a ES cells $(\mathrm{RCN} \beta \mathrm{H}(\mathrm{t})$, Fig. 5a, b). We conclude that Oct4 and Sox2 bind at the Rnf12 locus in a Nanog-independent fashion.

Inappropriate high levels of Rnf12 expression in inducible Oct4-null male ES cells

Should Oct 4 and Sox 2 act as repressors of Rnf12, then their permanent binding in the absence of Nanog might explain the mild upregulation of Rnf12 observed in Nanog-null ES cells. This situation would be strikingly similar to that previously observed for Xist. In the absence of Nanog, Xist is moderately upregulated in undifferentiated male ES cells. However, the acute silencing of Oct4 experimentally triggered in inducible Oct4-null male ES cells leads to differentiation and ectopic accumulation of Xist RNA at levels compatible with X-inactivation (Navarro et al. 2008). We sought to test whether in these particular conditions Rnf12 is expressed at female-like mRNA levels. To do this, we used ZHBTc4 male ES cells (Niwa et al. 2000). In these cells, both Oct4 alleles are deleted and a doxycycline-repressible Oct4 transgene supports Oct4 expression. Twenty-four hours after addition of doxycycline, Oct4 mRNA levels are completely abolished, whilst Nanog and Sox 2 remain expressed (Online Resource 1). This is associated with a 2 to threefold increase of Rnfl2 expression (Fig. 5c), indicating that Oct4 acts as a repressor of Rnf12. Strikingly, after 4 days of treatment, when Nanog and Sox2 are silenced (Online Resource) and Xist RNA levels were previously shown to be similar to those measured in differentiating female ES cells, Rnfl2 expression further increases to levels compatible with $\mathrm{X}$-inactivation as evaluated in differentiating female ES cells (Fig. 5c). Therefore, we conclude that Rnf 12 regulation by Nanog, Oct 4 and Sox 2 follows virtually identical principles than Xist regulation: Nanog, Oct4 and Sox 2 synergistically downregulate Rnf12 in undifferentiated ES cells.

\section{Discussion}

Previously, we and others have shown that in undifferentiated ES cells Xist is silenced by two independent 
mechanisms: (1) a direct transcriptional repression mediated by Nanog, Oct 4 and Sox 2 binding at Xist intron 1 (Navarro et al. 2008), and (2) a chromatin repression mediated by Tsix (reviewed in Navarro and Avner 2010), which is upregulated by the direct action of c-Myc, Klf4 and Rex1 binding at the primary Tsix enhancer DXPas34 (Navarro et al. 2010) and by Oct4, Sox 2 and Klf4 binding at the secondary Tsix enhancer Xite (Donohoe et al. 2009; Navarro et al. 2010). Neither Xist intron 1 deletion (Barakat et al. 2011), nor Tsix mutation (Lee and Lu 1999) is individually able to trigger $\mathrm{X}$-inactivation in undifferentiated ES cells, suggesting that either both systems cooperate to silence Xist, and/or that other systems of repression act in ES cells. It must be mentioned, however, that further analyses of the effects of Xist intron 1 deletion are required before rigorously concluding that it does not strongly affect $X i s t$ regulation. In undifferentiated ES cells, the Xist promoter is unable to efficiently recruit the transcriptional machinery, regardless of Tsix activity (Navarro et al. 2005). However, in the absence of Tsix, Xist RNA levels increase considerably in undifferentiated ES cells (Morey et al. 2001; Vigneau et al. 2006), suggesting Tsix might have post-transcriptional effects on Xist expression. Therefore, it is possible that in the absence of Xist intron 1, the transcriptional machinery is indeed efficiently recruited at the Xist promoter, Xist transcription readily enhanced, but Xist RNA post-transcriptionally repressed by $T$ six RNA. Thus, a ChIP analysis of Xist promoter state in Xist intron 1-deleted ES cells is absolutely required. Also, the analysis of double Xist intron 1/Tsix-mutants is required, and future work should specifically address this critical point.

Despite these considerations, additional mechanisms coupled to pluripotency might be involved in Xist suppression in ES cells. In this context, the results we report here expand our previous work on the coupling between $\mathrm{X}$-inactivation and pluripotency regulators. Indeed, we demonstrate Rnf12 is downregulated by Nanog, Oct 4 and Sox 2 , the three main actors of pluripotency. Interestingly, the sole overexpression of Rnf12 in female ES cells leads to $\mathrm{X}$-inactivation in the undifferentiated state (Barakat et al. 2011). Although the mechanisms of Rnf12 action at Xist are unknown, good evidence suggests it may activate the Xist promoter (Barakat et al. 2011). Therefore, the fact that Rnf12 is downregulated by Nanog, Oct4 and Sox 2 appears to be of critical importance in maintaining Xist silencing in undifferentiated ES cells. It is noteworthy that in all Nanog-and Oct4-null experimental conditions in which we previously reported ectopic Xist upregulation in male cells (Navarro et al. 2008), Rnf12 is also upregulated. Given the positive action exerted by Rnf12 on Xist, this suggests that all our previous observations on Xist might at least in part be due to Rnf12 upregulation rather than to a direct action of Nanog, Oct 4 and Sox 2 through Xist intron 1 binding. If this was to be true, the binding of these factors to Xist intron 1 would be extremely mysterious and perhaps functionally linked to the choice of the X-chromosome to be inactivated, as recently suggested (Barakat et al. 2011). We reiterate, however, that further work on the effects of Xist intron 1 deletion in undifferentiated ES cells is necessary before reaching these conclusions. Similarly, unequivocal proof that the binding events we have identified here directly inhibit Rnfl2 transcription should be provided in the future by targeting specific mutations that abrogate the binding.

Immuno-fluorescence analysis of Nanog and Rnf12 in ES cells has previously shown that Rnf12 is only consistently detected in Nanog-negative ES cells (Barakat et al. 2011). Nanog-negative and -positive cells have been shown to interconvert (Chambers et al. 2007), implying that Rnf12-negative and -positive cells may interconvert as well. This suggests that Nanog action at Rnf12 is reversible and strictly dependent on its expression, as supported by the restoration of normal levels of Rnf12 upon re-expression of Nanog in Nanog-null ES cells. To ultimately prove this single cell analysis, ideally by immunofluorescence, should be performed to follow the evolution of Nanog and Rnf12 protein levels during the growth of ES clones derived from single cells.

Initially viewed as a simple Xist-Nanog/Oct4/Sox2 connection, the system coupling $\mathrm{X}$-inactivation with pluripotency is rapidly expanding, first by the inclusion of Tsix as a direct target of Klf4, Rex 1 and c-Myc, and now with the repressive action of Nanog, Oct4 and Sox 2 on Rnf12 expression (Fig. 6). Strikingly, although our study has been restricted to Nanog, Oct4 and Sox2, additional transcription factors such as Klf4 and Esrrb, which have important roles in pluripotency (reviewed in Chambers and Tomlinson 2009), might also contribute to Rnf12 control as suggested by available ChIP-Seq data sets (Online Resource 2 ). This leads to a remarkably complex network of functional interactions between pluripotency and $\mathrm{X}$-inactivation regulators, a major emergent property of which might be the increase of the robustness of $\mathrm{X}$-inactivation inhibition in pluripotent compartments of the early embryo such as the ICM and the germ line. Furthermore, we believe the number of actors and nodes of this network is likely to grow further both by discovering other pluripotency factors acting on Xist, Tsix and Rnf12, and by finding new $\mathrm{X}$-linked regulators of $\mathrm{X}$-inactivation. For instance, two additional $\mathrm{X}$-linked non-coding genes have been recently shown to play a role in Xist regulation in ES cells: Ftx (Chureau et al. 2011) and Jpx (Tian et al. 2010). Both are located between Rnf12 and Xist and have been suggested to act as Xist activators through yet unknown mechanisms. Although it is unknown whether Ftx and/or Jpx overexpression leads to $\mathrm{X}$-inactivation in the undifferentiated state, their downregulation in ES cells may be important 


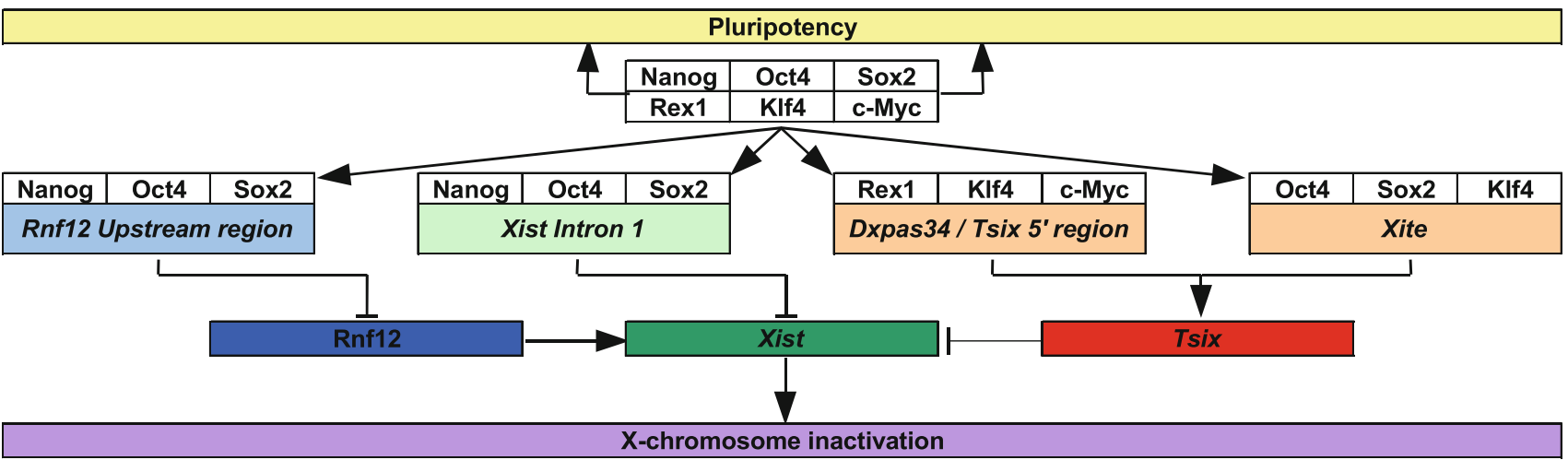

Fig. 6 Extended network coupling X-inactivation and pluripotency. The diagram depicts all known functional interactions between pluripotency and $\mathrm{X}$-inactivation regulators

for keeping Xist silent before differentiation. Strikingly, extensive binding of Nanog but not Oct4/Sox 2 is observed around Ftx in available ChIP-Seq data sets (Online Resource 2). In contrast, Jpx does not appear in ChIP-Seq studies as a target of Nanog or of any other pluripotencyassociated factor. Although additional work needs to be done to elucidate whether these two non-coding genes are also controlled by pluripotency transcription factors, it is increasingly clear that the road to pluripotency and the path of $\mathrm{X}$-inactivation are intrinsically connected through the direct control of many, if not all, $\mathrm{X}$-inactivation regulatory genes by the transcriptional machinery dedicated to pluripotency. The future establishment of the contribution of each individual factor to the control of $\mathrm{X}$-inactivation will undoubtedly shed light on our understanding of how genetic and epigenetic regulators functionally interact to bring the phenotype into being.

Acknowledgments The authors are grateful to Douglas Colby for technical assistance. Research in I.C.'s laboratory was supported by The Wellcome Trust and by the EU Framework 7 project "EuroSyStem". P.N was initially supported by funding from the UK Royal Society (Newton International Fellowship), then by the European Commission (Marie Curie Intra-European Fellowship for Career Development, FP7-PEOPLE-2009-IEF).

Conflict of interest All authors report no financial interests or potential conflicts of interest.

Open Access This article is distributed under the terms of the Creative Commons Attribution Noncommercial License which permits any noncommercial use, distribution, and reproduction in any medium, provided the original author(s) and source are credited.

\section{References}

Barakat TS, Gunhanlar N, Gontan Pardo C, Achame EM, Ghazvini M, Boers R, Kenter A, Rentmeester E, Grootegoed JA, Gribnau J
(2011) RNF12 activates Xist and is essential for X chromosome inactivation. PLoS Genet 7(1):e1002001

Borsani G, Tonlorenzi R, Simmler MC, Dandolo L, Arnaud D, Capra V, Grompe M, Pizzuti A, Muzny D, Lawrence C, Willard HF, Avner P, Ballabio A (1991) Characterization of a murine gene expressed from the inactive $X$ chromosome. Nature 351(6324): $325-329$

Brockdorff N, Ashworth A, Kay GF, Cooper P, Smith S, McCabe VM, Norris DP, Penny GD, Patel D, Rastan S (1991) Conservation of position and exclusive expression of mouse Xist from the inactive X chromosome. Nature 351(6324):329-331

Brown CJ, Ballabio A, Rupert JL, Lafreniere RG, Grompe M, Tonlorenzi R, Willard HF (1991) A gene from the region of the human $\mathrm{X}$ inactivation centre is expressed exclusively from the inactive X chromosome. Nature 349(6304):38-44

Chambers I, Tomlinson SR (2009) The transcriptional foundation of pluripotency. Development 136(14):2311-2322

Chambers I, Colby D, Robertson M, Nichols J, Lee S, Tweedie S, Smith A (2003) Functional expression cloning of Nanog, a pluripotency sustaining factor in embryonic stem cells. Cell 113(5):643-655

Chambers I, Silva J, Colby D, Nichols J, Nijmeijer B, Robertson M, Vrana J, Jones K, Grotewold L, Smith A (2007) Nanog safeguards pluripotency and mediates germline development. Nature 450(7173): 1230-1234

Chen X, Xu H, Yuan P, Fang F et al (2008) Integration of external signaling pathways with the core transcriptional network in embryonic stem cells. Cell 133(6):1106-1117

Chureau C, Chantalat S, Romito A, Galvani A, Duret L, Avner P, Rougeulle C (2011) Ftx is a non-coding RNA which affects Xist expression and chromatin structure within the $\mathrm{X}$-inactivation center region. Hum Mol Genet 20(4):705-718

Donohoe ME, Silva SS, Pinter SF, Xu N, Lee JT (2009) The pluripotency factor Oct 4 interacts with Ctcf and also controls $\mathrm{X}$-chromosome pairing and counting. Nature 460(7251):128 132

Eggan K, Akutsu H, Hochedlinger K, Rideout W, Yanagimachi R, Jaenisch R (2000) X-chromosome inactivation in cloned mouse embryos. Science 290(5496):1578-1581

Gardner RL, Lyon MF (1971) X chromosome inactivation studied by injection of a single cell into the mouse blastocyst. Nature 231(5302):385-386

Jonkers I, Barakat TS, Achame EM, Monkhorst K, Kenter A, Rentmeester E, Grosveld F, Grootegoed JA, Gribnau J (2009) RNF12 is an X-encoded dose-dependent activator of X chromosome inactivation. Cell 139(5):999-1011 
Lee JT, Lu N (1999) Targeted mutagenesis of Tsix leads to nonrandom $X$ inactivation. Cell 99(1):47-57

Lyon MF (1961) Gene action in the X-chromosome of the mouse (Mus musculus L.). Nature 190:372-373

Lyon MF (1962) Sex chromatin and gene action in the mammalian X-chromosome. Am J Hum Genet 14:135-148

Mak W, Nesterova TB, de Napoles M, Appanah R, Yamanaka S, Otte AP, Brockdorff N (2004) Reactivation of the paternal X chromosome in early mouse embryos. Science 303(5658): 666-669

Monk M, Kathuria H (1977) Dosage compensation for an X-linked gene in pre-implantation mouse embryos. Nature 270(5638):599-601

Morey C, Arnaud D, Avner P, Clerc P (2001) Tsix-mediated repression of Xist accumulation is not sufficient for normal random X inactivation. Hum Mol Genet 10(13):1403-1411

Mullin NP, Yates A, Rowe AJ, Nijmeijer B, Colby D, Barlow PN, Walkinshaw MD, Chambers I (2008) The pluripotency rheostat Nanog functions as a dimer. Biochem J 411(2):227-231

Navarro P, Avner P (2009) When X-inactivation meets pluripotency: an intimate rendezvous. FEBS Lett 583(11):1721-1727

Navarro P, Avner P (2010) An embryonic story: analysis of the gene regulative network controlling Xist expression in mouse embryonic stem cells. Bioessays 32(7):581-588

Navarro P, Pichard S, Ciaudo C, Avner P, Rougeulle C (2005) Tsix transcription across the Xist gene alters chromatin conformation without affecting Xist transcription: implications for X-chromosome inactivation. Genes Dev 19(12):1474-1484

Navarro P, Page DR, Avner P, Rougeulle C (2006) Tsix-mediated epigenetic switch of a CTCF-flanked region of the Xist promoter determines the Xist transcription program. Genes Dev 20(20):2787-2792

Navarro P, Chambers I, Karwacki-Neisius V, Chureau C, Morey C, Rougeulle C, Avner P (2008) Molecular coupling of Xist regulation and pluripotency. Science 321(5896):1693-1695

Navarro P, Chantalat S, Foglio M, Chureau C, Vigneau S, Clerc P, Avner P, Rougeulle C (2009) A role for non-coding Tsix transcription in partitioning chromatin domains within the mouse $\mathrm{X}$-inactivation centre. Epigenetics Chromatin 2(1):8

Navarro P, Oldfield A, Legoupi J, Festuccia N, Dubois A, Attia M, Schoorlemmer J, Rougeulle C, Chambers I, Avner P (2010) Molecular coupling of Tsix regulation and pluripotency. Nature 468(7322):457-460

Ng K, Pullirsch D, Leeb M, Wutz A (2007) Xist and the order of silencing. EMBO Rep 8(1):34-39

Niwa H, Miyazaki J, Smith AG (2000) Quantitative expression of Oct-3/4 defines differentiation, dedifferentiation or self-renewal of ES cells. Nat Genet 24(4):372-376
Ohhata T, Hoki Y, Sasaki H, Sado T (2008) Crucial role of antisense transcription across the Xist promoter in Tsix-mediated Xist chromatin modification. Development 135(2):227-235

Okamoto I, Otte AP, Allis CD, Reinberg D, Heard E (2004) Epigenetic dynamics of imprinted $\mathrm{X}$ inactivation during early mouse development. Science 303(5658):644-649

Plotnick F, Klinger HP, Kosseff AL (1971) Sex-chromatin formation in pre-implantation rabbit embryos. Cytogenetics 10(4):244-253

Rastan S, Robertson EJ (1985) X-chromosome deletions in embryoderived (EK) cell lines associated with lack of X-chromosome inactivation. J Embryol Exp Morphol 90:379-388

Sado T, Hoki Y, Sasaki H (2005) Tsix silences Xist through modification of chromatin structure. Dev Cell 9(1):159-165

Shin J, Bossenz M, Chung Y et al (2010) Maternal Rnf12/RLIM is required for imprinted $\mathrm{X}$-chromosome inactivation in mice. Nature 467(7318):977-981

Silva J, Nichols J, Theunissen TW, Guo G, van Oosten AL, Barrandon O, Wray J, Yamanaka S, Chambers I, Smith A (2009) Nanog is the gateway to the pluripotent ground state. Cell 138(4):722-737

Stadtfeld M, Maherali N, Breault DT, Hochedlinger K (2008) Defining molecular cornerstones during fibroblast to iPS cell reprogramming in mouse. Cell Stem Cell 2(3):230-240

Sun BK, Deaton AM, Lee JT (2006) A transient heterochromatic state in Xist preempts $\mathrm{X}$ inactivation choice without RNA stabilization. Mol Cell 21(5):617-628

Tada M, Takahama Y, Abe K, Nakatsuji N, Tada T (2001) Nuclear reprogramming of somatic cells by in vitro hybridization with ES cells. Curr Biol 11(19):1553-1558

Takagi N, Sasaki M (1975) Preferential inactivation of the paternally derived $\mathrm{X}$ chromosome in the extraembryonic membranes of the mouse. Nature 256(5519):640-642

Tian D, Sun S, Lee JT (2010) The long noncoding RNA, Jpx, is a molecular switch for $\mathrm{X}$ chromosome inactivation. Cell 143(3):390-403

Vigneau S, Augui S, Navarro P, Avner P, Clerc P (2006) An essential role for the DXPas34 tandem repeat and Tsix transcription in the counting process of $X$ chromosome inactivation. Proc Natl Acad Sci USA 103(19):7390-7395

Wutz A, Jaenisch R (2000) A shift from reversible to irreversible X inactivation is triggered during ES cell differentiation. Mol Cell 5(4):695-705

Yates A, Chambers I (2005) The homeodomain protein Nanog and pluripotency in mouse embryonic stem cells. Biochem Soc Trans 33(Pt 6):1518-1521 